
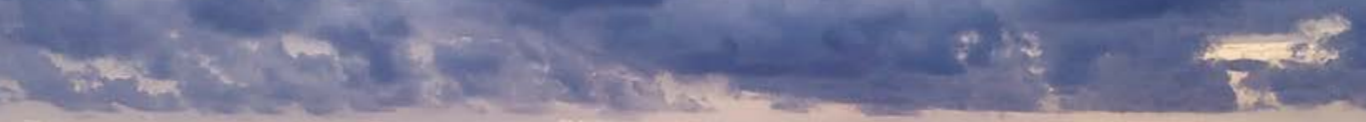

\title{
DEEP MEDITERRANEAN
} TURBULENT

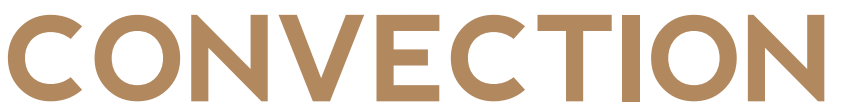

• Hans van Haren - https://doi.org/10.1051/epn/2020202 - e-mail: hans.van.haren@nioz.nl n NIOZ Royal Netherlands Institute for Sea Research and Utrecht University, P.O. Box 59, 1790 AB Den Burg, the Netherlands.

Life in the deep sea requires turbulent mixing and advective transporting water flows for the supply of nutrients. However, because of the harsh environmental constraints in the deep sea, detailed quantitative measurements are scarce. Recent high-resolution measurements demonstrate that the deep Mediterranean Sea waters are far from stagnant, even though temperature variations over a day and $100 \mathrm{~m}$ in depth are of the order of $0.0001^{\circ} \mathrm{C}$. An innovative 3D-mooring structure was used supporting 550 highly sensitive temperature sensors.

\section{Research in the Mediterranean Sea}

The Mediterranean Sea can be considered a large laboratory. In its (deep) waters, astrophysicists build a cubic kilometer large neutrino telescope to study fundamental particles of physics and far-away stellar systems [1]. Hydrodynamicists study geophysical flows at high Reynolds numbers between $10^{4}$ and $10^{7}$ that are difficult to generate elsewhere. Oceanographers see the Mediterranean as a test-basin for the larger oceans, in which nearly all relevant fluid dynamical and biogeochemical processes occur. While tides are virtually negligible in most of the Mediterranean, this sea is an example for studies on atmosphere-ocean exchange because of its evaporation surplus [2].

\section{Hydrodynamics}

in the Mediterranean Sea

In comparison with the open ocean, Mediterranean water depths are of the same order of magnitude with averages of 3700 and $1500 \mathrm{~m}$, respectively, but effects of distant atmospheric disturbances are less in the latter so that shipborne activities are slightly easier. In the Mediterranean deep sea the coast is relatively close. This proximity generates a fast response of current-flow generation by, e.g., wind, if it blows (or not) from mountain regions: Meltemi (Greece), Tramontane (Pyrenees), Mistral (Alps), Sirocco (Sahara) are 'on' or 'off'. The response in the sea is a generation of inertial waves, with mostly circular horizontal motions, via the Coriolis force. The 'on' or 'off' winds result in the generation of groups of inertial waves that, in the absence of $\triangle$ Mid-winter afternoon above the KM3NeT site near Toulon. About 2500 m deeper at the seabed the described data are recorded. Courtesy Ernst-Jan Buijs. 


\section{Detailed observations in the deep Mediterranean provide unprecedented opportunities as a hydrodynamic laboratory. Processes like natural (free) convection, internally forced convection, and current-shear play a role in this turbulent environment.}

tides, are the most important source of internal waves that can propagate into the interior of the sea at large depths. Internal waves are supported by the stable stratification in density, gravity waves, and variations in angular momentum of the rotating Earth, inertial waves in a stricter sense [3]. The latter occur as gyroscopic waves in near-homogeneous layers and have virtually only been observed in the Mediterranean [4]. Due to solar insolation at the surface of a water basin, relatively less dense warm water remains stably over deeper colder water. As molecular diffusion of heat is a relatively slow exchange process, the high Reynolds number environment causes turbulent vertical exchange to be dominant nearly everywhere in the sea. Two processes are distinguished [5]. First, shear-induced turbulence of vertical current-flow gradients destabilises a stable stratification. Second, turbulent 'natural' convection under gravity induced by cooling (generates relatively cold water) and evaporation (generates salty water) at the sea surface occur in many areas with vertical exchange down to typically 10 $\mathrm{m}$, especially during nighttime. At few sites convection occurs to greater depths: Near the poles (cold) and in the Mediterranean (salty). Coastal proximity and especially

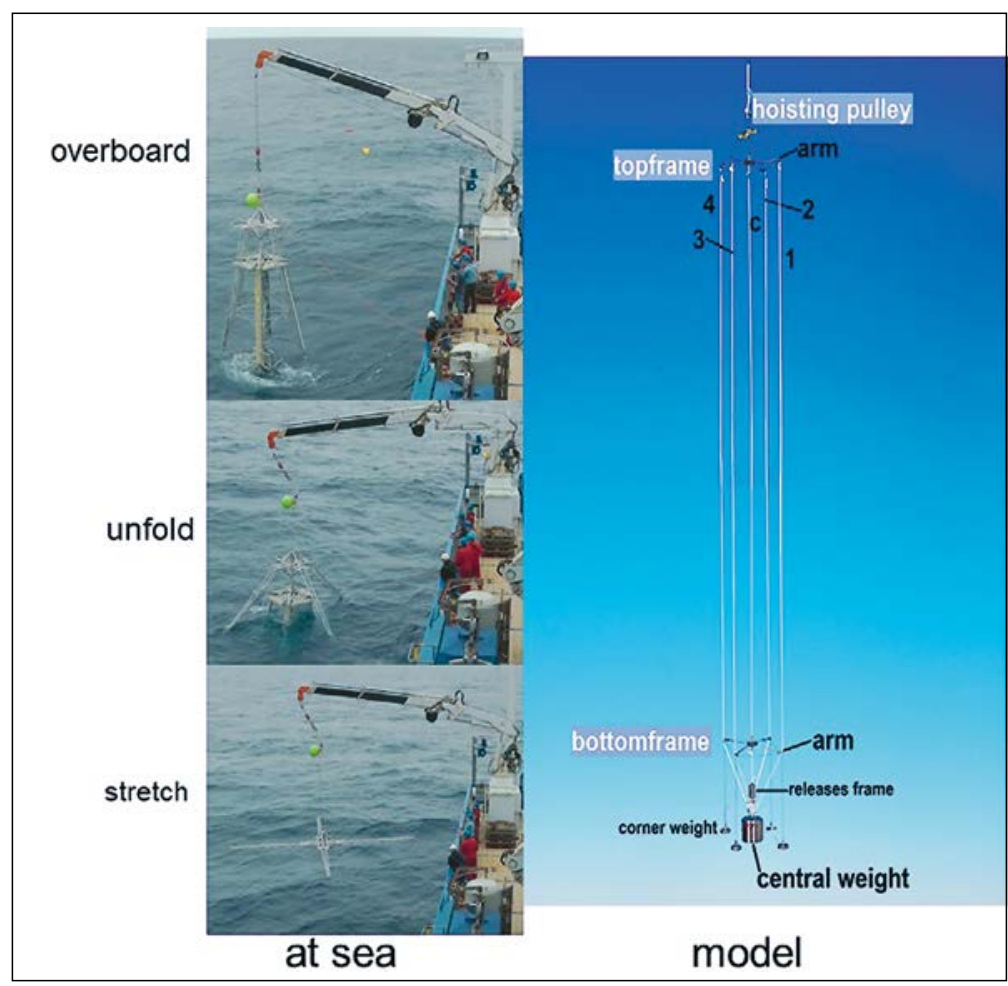

steep continental slopes show current-flows similar to the Gulf Stream and Kuroshio:Wind- and density-driven flows that become reinforced by natural convection [6] and which are important for transporting suspended materials. Studies on the (in)stability of these boundary flows, on associated meanderings and detached eddies, provide information on relatively rapid eddy-dynamic vertical transport of fresh biological materials from the sea surface to great depths and even the deep seafloor within a day [7].All aforementioned hydrodynamic processes occur near Toulon (France).

\section{Measuring turbulence}

\section{in the deep Mediterranean}

During the last decade, high-resolution sensors have been developed at NIOZ, the Royal Netherlands Institute for Sea Research, to record water temperature with a precision better than $0.0005^{\circ} \mathrm{C}$ and noise levels below $0.0001^{\circ} \mathrm{C}$. The sensors can withstand static pressure up to 1100 bar. The corrosive seawater is kept away from the micro-electronics via capillary glass-tubes, titanium housings and rubber O-rings. The salty seawater is used for closure of the electric circuit on clock-synchronisation of multiple stand-alone sensors. As a result, a vertical temperature profile can be measured over hundreds of metres within less than $0.02 \mathrm{~s}$. Recently, NIOZ developed a simple 3D-mooring structure consisting of five parallel lines $105 \mathrm{~m}$ long, 4 (and 5.6) $\mathrm{m}$ apart horizontally, that can hold 550 T-sensors. The lines are held under tension between two sets of arms that can be compacted into a $6 \mathrm{~m}$ tall structure on board. After being stretched overboard, it is lowered to the seafloor in free fall (Fig. 1). Between November 2017 and September 2018 this NIOZ 3D-mooring was deployed near one of the neutrino telescope sites of KM3NeT, $30 \mathrm{~km}$ offshore or Toulon, at $2480 \mathrm{~m}$ water depth.

\section{Sudden heating from above}

Generally, the deep Mediterranean water flow is weak with velocities less than $0.1 \mathrm{~m} \mathrm{~s}^{-1}$. Late winter, the flow-velocity increased up to $0.38 \mathrm{~m} \mathrm{~s}^{-1}$ and varied with 15 to 20 day periodicities due to boundary layer eddy-meandering. Only after August in summer, this late-winter intensification disappeared. In late winter, the boundary current along the continent intensifies, and with it turbulence processes intensify over the entire water column. Varying turbulence intensities have a vertical extent of $100 \mathrm{~m}$ and more. The sudden $0.002^{\circ} \mathrm{C}$ warming at day 430 passes the instrumentation in $1.5 \mathrm{~h}$ (Fig. 2). The warmer water structure has a length of about $700 \mathrm{~m}$, computed from observed mean flow-speed of $0.16 \mathrm{~m} \mathrm{~s}^{-1}$. The warming from above consists of multiple 'tubes' of alternating slightly warmer and colder water. This suggests typical convection, but it is not gravitationally driven by temperature instabilities, as the temperature stratification is stable. Possibly, the relatively warm waters are also relatively salty, to such extent that the density is statically unstable which generates natural 
convection. Alternatively, non-linear internal waves break and generate instability via (internally) forced convection from the waves' acceleration. The warm water passage is associated with an average of $0.03 \mathrm{~m} \mathrm{~s}^{-1}$ strong downward flow (Fig. 2a) and associates with $10 \mathrm{~dB}$ increase in acoustic reflectance off suspended particles (Fig. 2c).

\section{Sudden heating from below}

A few days later, a large column passes of near-homogeneous waters, having less than $0.1 \mathrm{mK}$ temperature variation over vertically $100 \mathrm{~m}$ and to within $0.5 \mathrm{~m}$ from the seafloor on day 439.05 (Fig. 3). This water is warmer than the environment and seems to (have) spread over the seafloor around the column. If salt does not contribute to density variations in this case, the observations can be one of natural convection, following large-scale homogenisation. Like in the previous example, small finger-like convective tubes are observed as if the seafloor is on fire. The large column has a diameter of $700 \mathrm{~m}$, given the $0.13 \mathrm{~m} \mathrm{~s}^{-1}$ average horizontal flow speed, it associates with an increase in acoustic reflection, and shows $-0.007 \mathrm{~m} \mathrm{~s}^{-1}$ mean vertical particle velocity.

\section{Continuation}

The observations demonstrate various hydrodynamic processes at great depths in the Mediterranean that have hardly been observed hitherto. Strong natural and (internally) forced convection besides shear-induced turbulence can only be observed using sensitive specialised instrumentation. The measurements demonstrate the feasibility of the new 3D-mooring. Presently at NIOZ, a larger unique $3 \mathrm{D}$-mooring is under construction with 45 lines and 3000 temperature sensors that will approximately fill a cubic hectometer to provide more insights in the development of deep-sea turbulence.

\section{About the author}

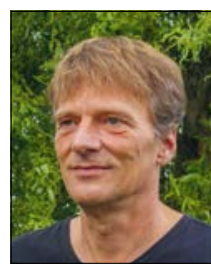

Hans van Haren is senior scientist in physical oceanography at the NIOZ, Royal Netherlands Institute for Sea Research Texel. His major research topics are tidal motions, internal waves and turbulent exchange in seas and oceans, which he studies via in-situ observations using custom-made instrumentation.

\section{Acknowledgements}

I am indebted to M. Laan, L. Gostiaux, D.-J. Buijsman and F. van Maarseveen for the pleasant cooperation during the development of NIOZ high-resolution temperature sensors. J. van Heerwaarden, R. Bakker and Y. Witte have developed and built various mechanical deployment structures. The temperature sensors are partially financed by NWO, the Netherlands Science Foundation.

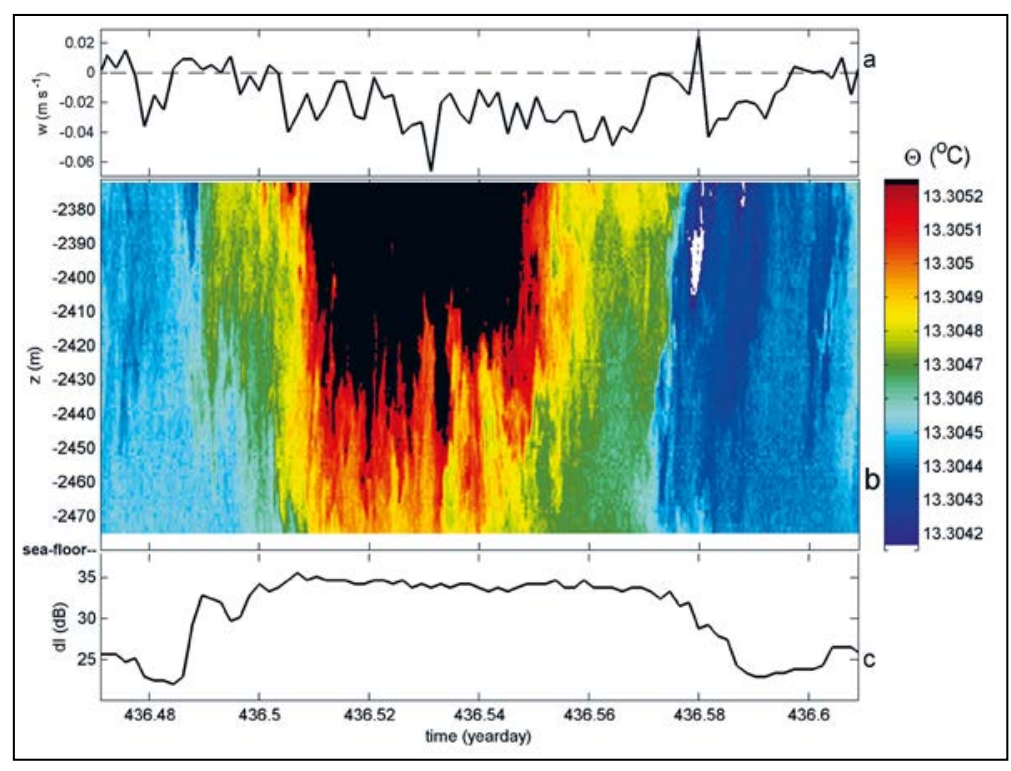

$\triangle$ FIG. 2:3.5 hours of temperature and flow observations during an eddy-passage of warm water in latewinter. (a) Time series of vertical velocity measured at $z=-2310 \mathrm{~m}$. (b) Time-depth image of corrected temperature from the $104 \mathrm{~T}$-sensors at the central line of the 3D-mooring. The lowest sensor is $5 \mathrm{~m}$ from the seafloor that is at the horizontal axis. (c). Time series of relative acoustic reflectance at $-2310 \mathrm{~m}$.

\section{References}

[1] S. Adrián-Martinez et al., J. Phys. G: Nucl. Part. Phys. 43, 084001 (2016).

[2] C. Garrett, In: P. Malanotte-Rizzoli, A. R. Robinson (eds.), Ocean Processes in Climate Dynamics: Global and Mediterranean examples, Kluwer, 227 (1994).

[3] P.H. LeBlond, L.A. Mysak, Waves in the Ocean, Elsevier, New York (1978).

[4] H. van Haren, C. Millot, Deep-Sea Res. / 51, 1441 (2004).

[5] H. Tennekes, J.L. Lumley, A first course in Turbulence, MIT Press, Boston (1972).

[6] M. Crépon, M. Boukhtir, B. Barnier, F. Aikman III, J. Phys. Oceanogr. 19, 1781 (1989).

[7] H. van Haren et al., Deep-Sea Res. I 58, 875 (2011).
vFIG. 3: As Fig. 2 ,

but for $8.5 \mathrm{~h}$

observations made

two days later.

In b. T-sensor

observations

are given from

cornerline- 1 that

reached to within

$0.5 \mathrm{~m}$ from the

seafloor.

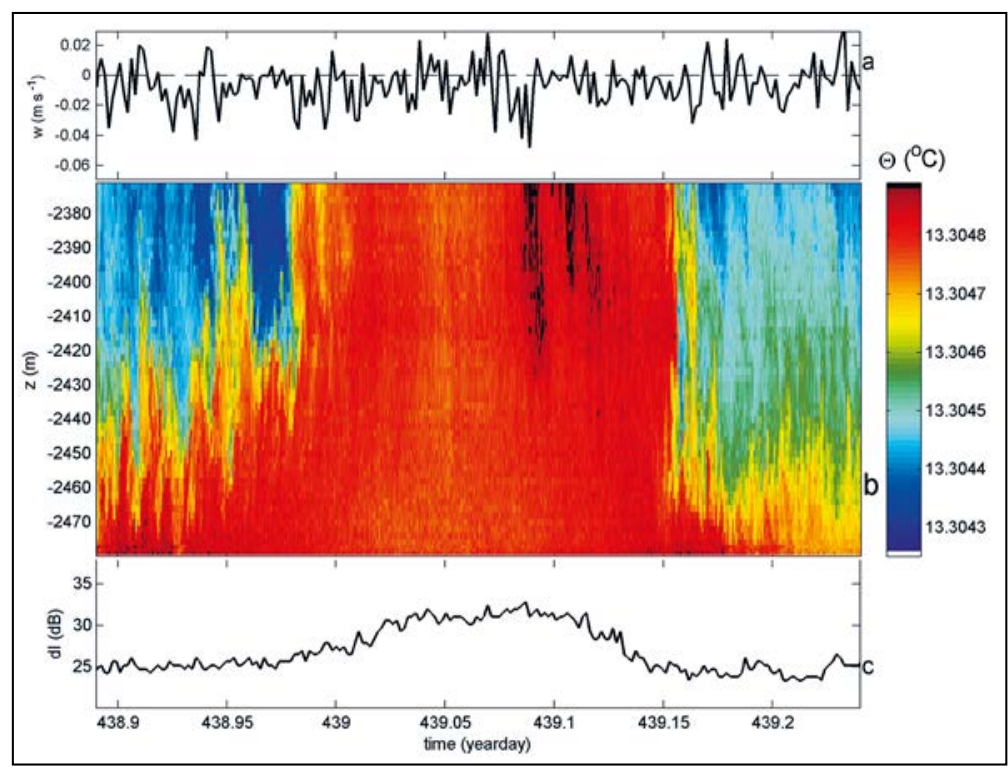

